\title{
Ni-Catalyzed Site-Selective Dicarboxylation of 1,3-Dienes with $\mathrm{CO}_{2}$
}

\author{
Andreu Tortajada, ${ }^{\dagger}$ Ryo Ninokata ${ }^{\dagger}$ and Ruben Martin $^{\dagger} \AA_{*}$ \\ $\dagger$ Institute of Chemical Research of Catalonia (ICIQ), The Barcelona Institute of Science and Technology, Av. Països Cata- \\ lans 16, 43007 Tarragona, Spain
}

§ ICREA, Passeig Lluïs Companys, 23, 08010, Barcelona, Spain

Supporting Information Placeholder

ABSTRACT: A site-selective catalytic incorporation of multiple $\mathrm{CO}_{2}$ molecules into 1,3-dienes en route to adipic acids is described. This protocol is characterized by its mild conditions, excellent chemo- and regioselectivity and ease of execution under $\mathrm{CO}_{2}(1 \mathrm{~atm})$, including the use of bulk butadiene and/or isoprene feedstocks.

The recent years have witnessed an emerging demand for catalytic techniques that forge multiple $\mathrm{C}-\mathrm{C}$ bonds via the synergistic combination of chemical feedstocks. ${ }^{1}$ Among various conceivable scenarios, a site-selective incorporation of carbon dioxide $\left(\mathrm{CO}_{2}\right)^{2}$ into olefin feedstocks in the absence of stoichiometric organometallic reagents is of particular relevance, ${ }^{3}$ holding promise to streamline the synthesis of industrially-relevant carboxylic acids. ${ }^{4}$ Despite the elegant advances realized, these carboxylation protocols remain currently confined to single $\mathrm{CO}_{2}$ insertions (Scheme 1, paths $a \& b$ ). ${ }^{5}$ Therefore, the ability to expand the catalytic carboxylation portfolio of $\mathrm{C}=\mathrm{C}$ bonds beyond single $\mathrm{CO}_{2}$ insertions would be a worthwhile endeavour, opening up new strategies for preparing saturated polycarboxylic acids. ${ }^{6}$

Scheme 1. Carboxylation of Olefinic $\mathrm{C}=\mathrm{C}$ Bonds. a state-of-the-art catalytic carboxylation of olefinic $\mathrm{C}=\mathrm{C}$ bonds with $\mathrm{CO}_{2}$

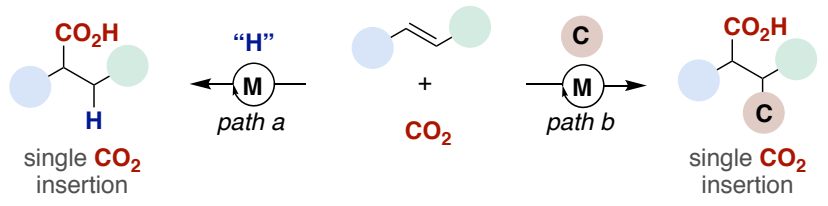

this work: site-selective multiple catalytic $\mathrm{CO}_{2}$ insertions into 1,3-dienes

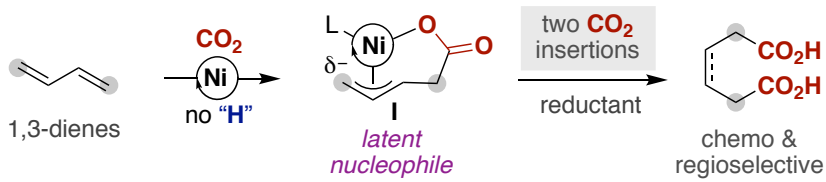

As part of our ongoing interest in $\mathrm{CO}_{2},{ }^{7}$ we questioned whether we could enable a catalytic, siteselective incorporation of multiple $\mathrm{CO}_{2}$ motifs into abundant 1,3-dienes en route to adipic acids, ${ }^{8}$ building blocks of particular relevance in the production of plastics and adhesives. ${ }^{9}$ If successful, this pathway might also offer an opportunity to complement recent catalytic difunctionalization of 1,3 -dienes, ${ }^{10}$ as raw materials $\left(\mathrm{CO}_{2}\right)$ would be used as electrophilic carbon synthons in lieu of nucleophilic reagents. ${ }^{11}$ However, such a scenario bears considerable risk and might seem counterintuitive at first sight due to (a) the proclivity of 1,3-dienes to trigger telomerization reactions ${ }^{12}$ and (b) the fact that statistical mixtures of monocarboxylic acids were exclusively observed with hydrocarboxylation conditions previously employed for either alkynes ${ }^{13}$ or alkenes, ${ }^{5 b}$ reinforcing the notion that a multiple, yet controllable, $\mathrm{CO}_{2}$ insertion event would be particularly problematic. We anticipated that a site- 
selective insertion of multiple $\mathrm{CO}_{2}$ units could be rationally controlled in the absence of hydride sources by exploiting the inherent carbogenic nucleophilicity of I (Scheme 1, bottom). ${ }^{14}$ Upon $\pi-\sigma$ equilibration, the targeted adipic acids could be obtained by a subsequent regioselective $\mathrm{CO}_{2}$ incorporation into I that precedes a final reduction to recover back the catalytic $\mathrm{Ni}(0) L_{n}$ species. Herein, we report the successful realization of this goal, culminating in a mild method that operates at atmospheric pressure of $\mathrm{CO}_{2}$ and is characterized by its chemo- and regioselectivity profile, including the ability to use of bulk butadiene and/or isoprene feedstocks.

Table 1. Optimization of the Reaction Conditions. ${ }^{a}$

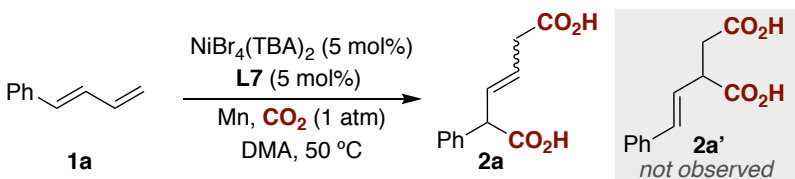

\begin{tabular}{|c|c|}
\hline Entry & Deviation from standard conditions \\
\hline 1 & None \\
\hline 2 & Using $\mathrm{NiBr}_{2} \cdot$ glyme \\
\hline 3 & Using $\mathrm{Ni}(\mathrm{COD})_{2}$ \\
\hline 4 & L1 instead of L7 \\
\hline 5 & L2 instead of L7 \\
\hline 6 & L3 instead of L7 \\
\hline 7 & L4 instead of L7 \\
\hline 8 & L5 instead of L7 \\
\hline 9 & L6 instead of L7 \\
\hline 10 & DMF (NMP) as solvent \\
\hline 11 & $\mathrm{Zn}$ instead of $\mathrm{Mn}$ \\
\hline 12 & No $\mathrm{NiBr}_{4}(\mathrm{TBA})_{2}$, no L7 or no $\mathrm{Mn}$ \\
\hline
\end{tabular}

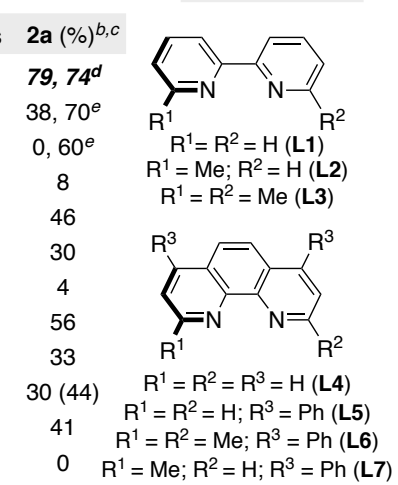

${ }^{a}$ 1a $(0.20 \mathrm{mmol}), \mathrm{NiBr}_{4}(\mathrm{TBA})_{2}(5 \mathrm{~mol} \%), \mathbf{L 7}(5 \mathrm{~mol} \%)$, Mn (1.50 equiv), $\mathrm{CO}_{2}$ (1 bar), DMA (0.5 M), $50{ }^{\circ} \mathrm{C} .{ }^{b} \mathrm{Z} / \mathrm{E}=$ 1.4:1 to $5: 1 .{ }^{c} \mathrm{H}-\mathrm{NMR}$ yields using fluorene as internal standard. ${ }^{d}$ Isolated yield. ${ }^{e}$ with TBAB (10 mol\%). TBAB: tetrabutylammonium bromide, TBA: tetrabutylammonium.

We began our investigations by studying the reaction of 1 a with $\mathrm{CO}_{2}(1 \mathrm{~atm})$. After some experimentation, ${ }^{15}$ a cocktail consisting of $\mathrm{NiBr}_{4}(\mathrm{TBA})_{2}$, L7 and $\mathrm{Mn}$ as reductant in DMA at $50{ }^{\circ} \mathrm{C}$ furnished 2a $(Z / E=$ $2.4: 1)$ in $74 \%$ isolated yield. It is worth noting that not even traces of $\mathbf{2} \mathbf{a}^{\prime}$ or telomerization sideproducts were observed in the crude mixtures. Intriguingly, the absence of ammonium salts resulted in a markedly lower reactivity (entries 2 and 3). ${ }^{16} \mathrm{~A}$ detailed survey of nitrogen-donor ligands revealed that a seemingly trivial modification at C2 was critical for success (entries 4 vs 5-6). Unlike recent reductive carboxylations, ${ }^{17}$ the presence of substituents at both 2,2'-positions had a deleterious effect (entry 9 vs 1), thus showing the subtleties of our protocol. The use of other precatalysts (entries 2 and 3), solvents (entry 10) or reductants (entry 11) had a detrimental impact on reactivity. ${ }^{18}$ Notably, identical results were observed regardless of whether $(E)$-1a or (Z)-1a were used, constituting an additional bonus from a synthetic and practical standpoint. ${ }^{19}$ As expected, control experiments revealed no product formation when each parameter was omitted from the mixture (entry 12). ${ }^{15}$

Table 2. Ni-catalyzed 1,4-Dicarboxylation of 1,3-Dienes.

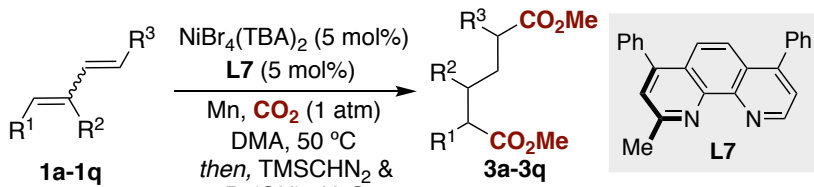
$\mathrm{B}_{2}(\mathrm{OH})_{4}-\mathrm{H}_{2} \mathrm{O}$

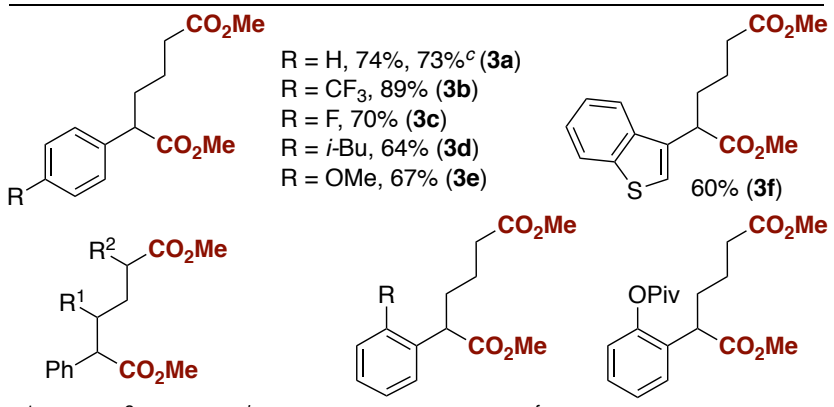

$\mathrm{R}^{1}=\mathrm{Me} ; \mathrm{R}^{2}=\mathrm{H} ; \mathbf{7 5} \%^{d}(\mathbf{3 g}) \quad \mathrm{R}=\mathrm{Me}, 90 \%, 82 \%{ }^{f}(\mathbf{3 i})$ $\mathrm{R}^{1}=\mathrm{H} ; \mathrm{R}^{2}=\mathrm{Me} ; 68 \%^{e}(\mathbf{3 h}) \quad \mathrm{R}=\mathrm{CO}_{2} \mathrm{Me}, 81 \%(\mathbf{3 j}) \quad 89 \%(\mathbf{3 k})$

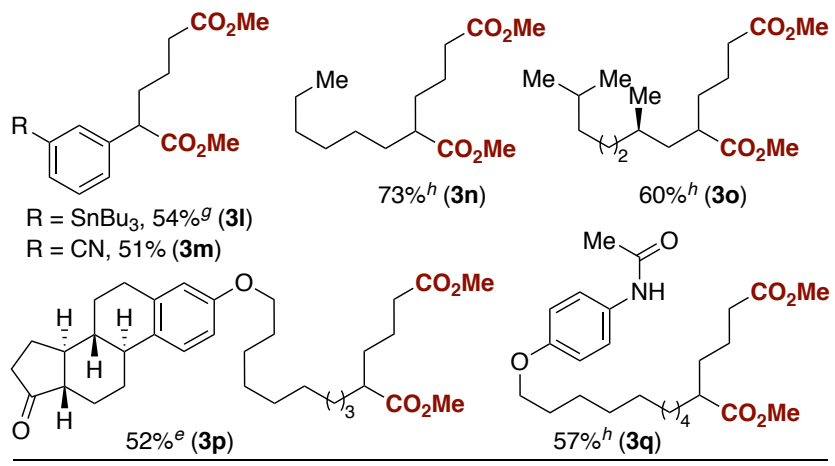

${ }^{a}$ As Table 1 (entry 1), followed by exposure to $\mathrm{TMSCHN}_{2}$ and $\mathrm{Pd} / \mathrm{C}$ (5 mol\%), $\mathrm{B}_{2}(\mathrm{OH})_{4}(2$ equiv) and $\mathrm{H}_{2} \mathrm{O}$ (5 equiv) at rt. ${ }^{b}$ Isolated yields, average of two independent runs, using 1,3-dienes as $E / Z$ mixtures. ${ }^{c}$ Using $\boldsymbol{E}$-1a. ${ }^{d} \mathrm{dr}=1.5: 1 .{ }^{e} \mathrm{dr}=1: 1 .{ }^{f} 1 \mathrm{mmol}$ scale. ${ }^{g}$ Using $\mathrm{H}_{2}$ and $\mathrm{Pd} / \mathrm{C}$ as reductant. ${ }^{h} \mathrm{NiBr}_{4}(\mathrm{TBA})_{2}(10$ $\mathrm{mol} \%$ ) and L7 (10 mol\%).

Once we established the optimized reaction conditions, we next studied the generality of our catalytic dicarboxylation of 1,3-dienes (Table 2). ${ }^{19}$ In situ protection of the carboxylic acid function as the methyl ester and reduction of the pending alkene was necessary to avoid unnecessary purification issues of the resulting adipic acid derivatives. ${ }^{20}$ As expected, a host of 1,3-dienes substituted with either aliphatic (1n-1q) or aromatic backbones (1a-1m) reacted equally well with the $\mathrm{NiBr}_{4}(\mathrm{TBA})_{2} / \mathbf{L} 7$ couple. Notably, the outcome of the latter was found to be insensitive to whether electronrich or electron-poor arenes were employed, even in the 
presence of ortho-substituents (1i-1k). The site-selective incorporation of multiple $\mathrm{CO}_{2}$ motifs into 1,3-dienes was accompanied by an excellent chemoselectivity, as esters $(\mathbf{3} \mathbf{j}, \mathbf{3 k})$, nitriles $(\mathbf{3} \mathbf{m})$, ketones $(\mathbf{3} \mathbf{p})$ or amides $(\mathbf{3 q})$ were well-tolerated. Interestingly, the presence of an organometallic reagent does not interfere with productive formation of 31, thus demonstrating the complementarity of our technique with classical nucleophilic/electrophilic regimes. ${ }^{21,22}$ Likewise, the reaction could be applied in the presence of heterocyclic cores (3f). As illustrated by the successful preparation of $\mathbf{3} \mathbf{g}$ and $\mathbf{3 h}$, the reaction could also be extended to disubstituted 1,3-dienes, albeit with lower diastereoselectivities. Although $\mathrm{C}-\mathrm{O}$ electrophiles are inherently predisposed to nickel-catalyzed $\mathrm{C}-$ $\mathrm{C}$ bond-forming reactions, ${ }^{23}$ we found that $\mathbf{3 k}$ could be obtained in $89 \%$ yield, leaving ample room for further derivatization via cross-coupling technologies.

Scheme 2. Ni-catalyzed Carboxylation of Diene Feedstocks.

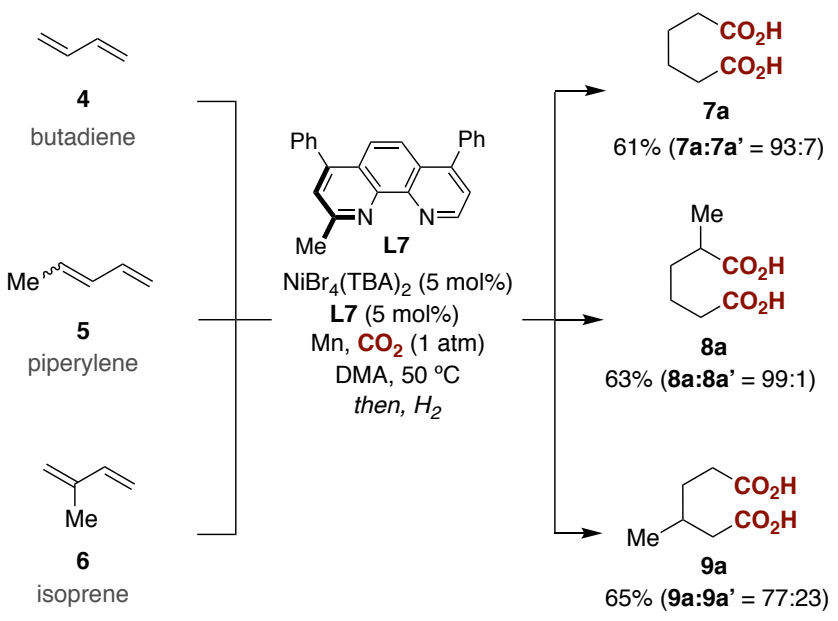

In light of these results, we wondered whether our protocol could be used for the valorization of butadiene, isoprene or piperylene, compounds that are obtained in bulk as byproducts of the steam cracking in the production of ethylene. ${ }^{24}$ As shown in Scheme 2, this turned out to be the case, and 7a-9a were all obtained in good yields from the corresponding 1,3-diene feedstocks after a subsequent hydrogenolysis event. Strikingly, butadiene 4 resulted in a 93:7 regioselectivity pattern whereas the presence of a methyl group in either 5 or $\mathbf{6}$ had a nonnegligible effect on site-selectivity, with $\mathbf{5}$ providing the best regiochemical discrimination $(\mathbf{8 a}){ }^{25}$ Although the 1,4-ratio of 7a and 9a could partially be improved by using either $\mathbf{L 5}$ or $\mathbf{L 2}$ in lieu of $\mathbf{L} 7$, significant lower yields were observed in these cases. ${ }^{15}$ Taken together, the results summarized in Table 2 and Scheme 2 stand as a testament to the potential of this catalytic technology for enabling a site-selective incorporation of multiple $\mathrm{CO}_{2}$ units into abundant 1,3-diene precursors.

\section{Scheme 3. Mechanistic Experiments.}

- stereochemical course of the dicarboxylation event

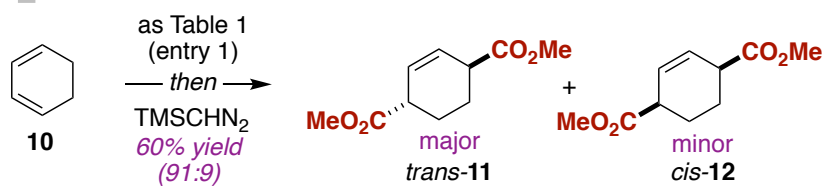

口 stoichiometric studies with $\mathrm{Ni}(0)(\mathrm{L} 7)_{\mathrm{n}}$
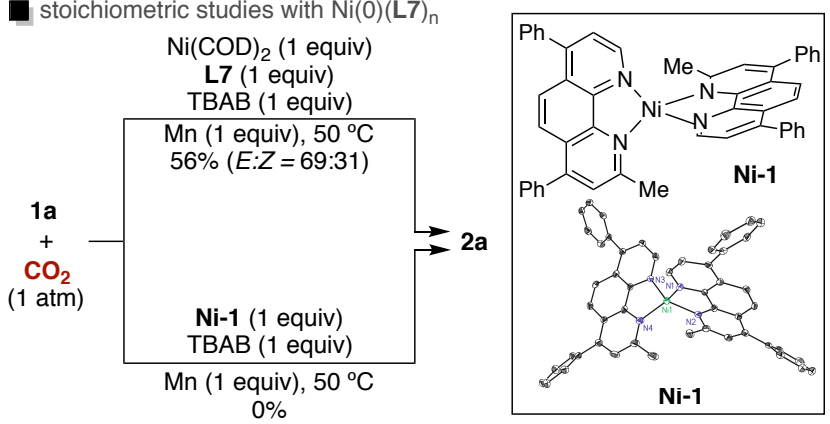

stoichiometric studies with $\mathrm{Ni}-2$
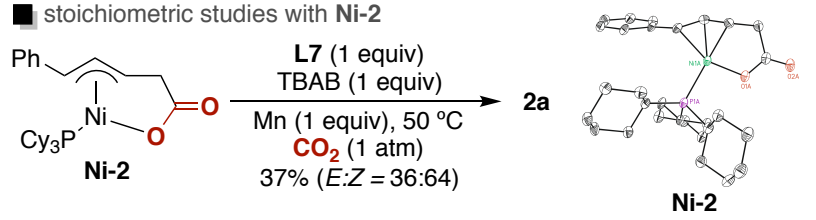

Next, we decided to gather indirect evidence about the mechanism by studying the stereochemical course of $\mathbf{1 0}$ with $\mathrm{CO}_{2}$ (Scheme 3, top). Interestingly, trans-11 was preferentially formed over cis-12, suggesting that the second $\mathrm{CO}_{2}$ unit is inserted into the $\pi$-allyl complex $\mathbf{I}$ (Scheme 1) via formal backside attack. ${ }^{26}$ This seemingly trivial interpretation, however, does certainly not rule out a rapid interconversion of the putative $\pi$-allyl nickel complexes upon exposure to $\mathrm{Ni}(0)(\mathbf{L} 7)$ prior to $\mathrm{CO}_{2}$ insertion. ${ }^{27}$ Although unraveling the mechanistic underpinnings of this reaction should await further investigations, we turned our attention to study the reactivity of Ni-1 (Scheme 3, middle). This complex was easily prepared by exposure of $\mathbf{L} 7$ and $\mathrm{Ni}(\mathrm{COD})_{2}$ in benzene at 40 ${ }^{\circ} \mathrm{C}$, the structure of which was univocally determined by X-ray crystallography. ${ }^{15}$ Interestingly, the reactivity of Ni-1 with 1a was not comparable to that observed with $\mathrm{Ni}(\mathrm{COD})_{2} / \mathbf{L} 7$, with not even traces of $\mathbf{2 a}$ being observed in the former. ${ }^{28}$ While one might attribute this finding to the non-innocent role of $\mathrm{COD},{ }^{29}$ the reluctance of coordinatively saturated Ni-1 to dissociate $\mathbf{L} 7$ prior to 1,3-diene binding seems more likely. Unfortunately, the preparation of $\pi$-allyl complex I (Scheme 1) in pure analytical form bearing $\mathbf{L} 7$ as ligand proved to be particularly elusive. Gratifyingly, we could prepare structurally-related $\mathbf{N i - 2}$, and the $\eta^{3}$-hapticity of the allyl motif was finally revealed by X-ray structure analysis (bottom). ${ }^{15}$ Interestingly, we found that Ni-2 only furnished 2a in the presence of both $\mathbf{L 7}$ and $\mathbf{M n} .^{15,30}$ Whether these results suggest that single-electron transfer processes come into play via putative $\mathrm{Ni}(\mathrm{I})$ species $^{31}$ or invoke other mechanistic interpretations is the subject of ongoing studies. 
In summary, we have documented a site-selective, catalytic incorporation of multiple $\mathrm{CO}_{2}$ molecules into abundant 1,3-dienes, thus giving access to adipic acids from simple and available precursors. The salient features of this method are its excellent regio- and chemoselectivity, mild conditions and ease of execution. Further extensions to other hydrocarbons, including asymmetric transformations, are currently in progress.

\section{ASSOCIATED CONTENT}

Supporting Information. Experimental procedures, crystallographic data and spectral data. This material is available free of charge via the Internet at http://pubs.acs.org.

\section{AUTHOR INFORMATION}

\section{Corresponding Author}

*rmartinromo@iciq.es

Funding Sources

No competing financial interests have been declared.

\section{ACKNOWLEDGMENT}

We thank ICIQ, MINECO (CTQ2015-65496-R \& Severo Ochoa Accreditation SEV-2013-0319) for support. A. T. thanks MINECO for a FPU fellowship. We sincerely thank M. Martínez, E. Escudero \& E. Martin for X-ray crystallographic data and Dr. M. Gaydou for helpful discussions.

\section{REFERENCES}

(1) Colacot, T. New Trends in Cross-Coupling; Royal Society of Chemistry: Cambridge, 2015.

(2) (a) Juliá-Hernández, F.; Gaydou, M.; Serrano, E.; van Gemmeren, M.; Martin, R. Top. Curr. Chem. 2016, 374, 45. (b) Börjesson, M.; Moragas, T.; Gallego, D.; Martin, R. ACS Catal. 2016, 6, 6739. (c) Liu, Q.; Wu, L.; Jackstell, R.; Beller, M. Nat. Commun. 2015, 6, 5933. (d) Zhang, L.; Hou, Z. Chem. Sci. 2013, 4, 3395. (e) Tsuji, Y.; Fujihara, T. Chem. Commun. 2012, 48, 9956.

(3) For selected homogeneous metal-catalyzed carboxylations of $\mathrm{C}=\mathrm{C}$ bonds with stoichiometric organometallic reagents: (a) Higuchi, Y.; Mita, T.; Sato, Y. Org. Lett. 2017, 19, 2710. (b) Greenhalgh, M. D.; Thomas, S. P. J. Am. Chem. Soc. 2012, 134, 11900. (c) Williams, C. M.; Johnson, J. B.; Rovis, T. J. Am. Chem. Soc. 2008, 130, 14936.

(4) Maag, H.Prodrugs of Carboxylic Acids; Springer: New York, 2007.

(5) For recent catalytic carboxylations of olefins via single $\mathrm{CO}_{2}$ insertions in the absence of organometallics: (a) Ye, J. H.; Miao, M.; Huang, H.; Yan, S. S.; Yin, Z. B.; Zhou, W. J.; $\mathrm{Yu}$, D. G. Angew. Chem. Int. Ed. 2017, 56, 15416. (b) Gaydou, M.; Moragas, T.; Juliá-Hernández, F.; Martin, R. J. Am. Chem. Soc. 2017, 139, 12161. (c) Seo, H.; Liu, A.; Jamison, T. F. J. Am. Chem. Soc. 2017, 139, 13969. (d) Yatham, V. R.; Shen, Y.; Martin, R. Angew. Chem. Int. Ed. 2017, 56, 10915. (e) Murata, K.; Numasawa, N.; Shimomaki, K.; Takaya, J.; Iwasawa, N. Chem. Commun. 2017, 53, 3098. (f) Wu, L.; Liu, Q.; Fleischer, I.; Jackstell, R.; Beller, M. Nat. Commun. 2014, 5, 3091. (g) Ostapowicz, T. G.; Schmitz, M.; Krystof, M.; Klankermayer, J.; Leitner, W. Angew. Chem. Int. Ed. 2013, 52, 12119.
(6) For an isolated Ni-catalyzed 1,2-dicarboxylation of endcapped silyl allenes requiring excess amounts of DBU and pyrophoric $\mathrm{Et}_{2} \mathrm{Zn}$ as reducing agent: Takimoto, M.; Kawamura, M.; Mori, M.; Sato, Y. Synlett 2005, 2019. For a catalytic route to maleic anhydrides from alkyne derivatives: Fujihara, T.; Horimoto, Y.; Mizoe, T.; Sayyed, F. B.; Tani, Y.; Terao, J.; Sakaki, S.; Tsuji, Y. Org. Lett. 2014, 16, 4960.

(7) For recent references: (a) Juliá-Hernández, F.; Moragas, T.; Cornella, J.; Martin, R. Nature 2017, 545, 84. (b) van Gemmeren, M.; Börjesson, M.; Tortajada, A.; Sun, S.-Z.; Okura, K.; Martin, R. Angew. Chem. Int. Ed. 2017, 56, 6558. (c) Moragas, T.; Gaydou, M.; Martin, R. Angew. Chem. Int. Ed. 2016, 55, 5053. (d) Börjesson, M.; Moragas, T.; Martin, R. J. Am. Chem. Soc. 2016, 138, 7504. (e) refs. 5b and 5d.

(8) For seminal studies that required stoichiometric amounts of nickel complexes: (a) Hoberg, H.; Schaefer, D.; Oster, B. W. J. Organomet. Chem. 1984, 266, 313. (b) Behr, A.; Kanne, U. J. Organomet. Chem. 1986, 317, 41. (c) Takimoto, M.; Mori, M. J. Am. Chem. Soc. 2001, 123, 2895.

(9) (a) Van de Vyver, S.; Román-Leshkov, Y. Catal. Sci. Technol. 2013, 3, 1465. (b) Musser, M. T. In Ullmann's Encyclopedia of Industrial Chemistry; Wiley-VCH Verlag GmbH \& Co. KGaA: Weinheim, Germany, 2000; pp 1-11.

(10) For selected references: (a) Thullen, S. M.; Rovis, T. J. Am. Chem. Soc. 2017, 139, 15504. (b) Sardini, S. R.; Brown, M. K. J. Am. Chem. Soc. 2017, 139, 9823. (c) Yang, X. H.; Dong, V. M. J. Am. Chem. Soc. 2017, 139, 1774. (d) Yang, X. H.; Lu, A.; Dong, V. M. J. Am. Chem. Soc. 2017, 139, 14049. (e) McCammant, M. S.; Sigman, M. S. Chem. Sci. 2015, 6, 1355. (f) Saito, N.; Kobayashi, A.; Sato, Y. Angew. Chem. Int. Ed. 2012, 51, 1228, and citations therein.

(11) While this publication was under preparation, an elegant $\mathrm{Cu}$-catalyzed hydroxymethylation of 1,3-dienes via single $\mathrm{CO}_{2}$ insertion was developed: Gui, Y. $-\mathrm{Y}$.;Hu, N.; Chen, X. -W.; Liao, L. -L.; Ju, T.; Ye, J. -H.; Zhang, Z.; Li, J.; Yu, D. -G. J. Am. Chem. Soc. 2017, 139, 17011.

(12) Selected references: (a) Sharif, M.; Jackstell, R.; Dastgir, S.; Al-Shihi, B.; Beller, M. ChemCatChem, 2017, 9, 542. (b) Bruijnincx, P. C. A.; Jastrzebski, R.; Hausoul, P. J. C.; Gebbink, R. J. M. K.; Weckhuysen, B. M. Top. Organomet. Chem. 2012, 39, 45. (c) Hoberg, H.; Gross, S.; Milchereit, A. Angew. Chem Int. Ed. 1987, 26, 571.

(13) (a) Doi, R.; Abdullah, I.; Taniguchi, T.; Saito, N.; Sato, Y. Chem. Commun. 2017, 53, 7720. (b) Wang, X.; Nakajima, M.; Martin, R. J. Am. Chem. Soc. 2015, 137, 8924. (c) Li, S.; Yuan, W.; Ma, S. Angew. Chem. Int. Ed. 2011, 50, 2578. (d) Fujihara, T.; Xu, T.; Semba, K.; Terao, J.; Tsuji, Y. Angew. Chem. Int. Ed. 2011, 50, 523.

(14) (a) Hoberg, H.; Apotecher, B. J. Organomet. Chem. 1984, 270 , c15. (b) Walther, D.; Dinjus, E.; Görls, H.; Sieler, J.; Lindqvist, O.; Andersen, L. J. Organomet. Chem. 1985, $286,103$.

(15) For details, see Supporting Information.

(16) Ammonium salts have been reported to speed up the reduction of nickel by Mn: (a) Iyoda, M.; Otsuka, H.; Sato, K.; Nisato, N.; Oda, M. Bull. Chem. Soc. Jpn. 1990, 63, 80. (b) Fujihara, T.; Nogi, K.; Xu, T.; Terao, J.; Tsuji, Y. J. Am. Chem. Soc. 2012, 134, 9106.

(17) For selected references in which ortho-substituents on the nitrogen ligand exerted a critical influence on carboxylation reactions, see: (a) ref. 7. (b) Nogi, K.; Fujihara, T.; Terao, J.; Tsuji, Y. J. Org. Chem. 2015, 80, 11618.

(18) The use of organic reductants or $\mathrm{Me}_{2} \mathrm{Zn}$ instead of $\mathrm{Mn}$ as reducing agents led to no formation of $2 \mathbf{a}$. See ref 15 .

(19) The mass balance accounts for unreacted starting material and competitive polymerization of the 1,3-diene. Notably, no reaction took place under $\mathrm{CO}_{2}$ pressure (10 bars). 
(20) Regardless of whether aromatic or aliphatic dienes were employed, $Z: E$ selectivities ranging from $1.5: 1$ to $2.5: 1$ were obtained. Competitive olefin isomerization was prevented by conducting the hydrogenolysis with $\mathrm{B}_{2}(\mathrm{OH})_{4}-\mathrm{H}_{2} \mathrm{O}$; Cummings, S. P.; Le, T.-N.; Fernandez, G. E.; Quiambao, L. G.; Stokes, B. J. J. Am. Chem. Soc. 2016, 138, 6107.

(21) Metal-Catalyzed Cross-Coupling Reactions; Wiley-VCH Verlag GmbH: Weinheim, Germany, 2008.

(22) Not even traces of benzoic acid from $\mathrm{CO}_{2}$ insertion into the $\mathrm{C}-\mathrm{Sn}$ bond were observed in the crude mixtures. For the direct carboxylation of organometallic reagents: Correa, A.; Martin, R. Angew. Chemie Int. Ed. 2009, 48, 6201.

(23) For selected reviews dealing with $\mathrm{C}-\mathrm{O}$ bond-cleavage of aryl esters, see: (a) Zarate, C.; Van Gemmeren, M.; Somerville, R. J.; Martin, R. Adv. Organomet. Chem. 2016, 66, 143. (b) Su, B.; Cao, Z. -C.; Shi, Z. -J. Acc. Chem. Res. 2015, 48, 886. (c) Rosen, B. M.; Quasdorf, K. W.; Wilson, D. A.; Zhang, N.; Resmerita, A.-M.; Garg, N. K.; Percec V. Chem. Rev. 2011, 111, 1346.

(24) Weissermel, K.; Arpe, H. In Industrial Organic Chemistry; Wiley-VCH Verlag GmbH: Weinheim, Germany, 2007; 105.
(25) Although tentative, these results can be interpreted on the basis of a subtle influence on both steric and electronic effects on the reactivity of $\pi$-allyl complex I (Scheme 1).

(26) This finding is in excellent agreement with conclusions previously reached by Sato with stoichiometric amounts of Ni complexes and pyrophoric reagents. See ref. 8c.

(27) Such interpretation was invoked by Jarvo in non-related stereospecific Ni-catalyzed reactions. See: Yonova, I. M.; Johnson, A. G.; Osborne, C. A.; Moore, C. E.; Morrissette, N. S.; Jarvo, E. R. Angew. Chemie Int. Ed. 2014, 53, 2422.

(28) Control experiments revealed that the $\mathrm{Ni}(0) / \mathbf{L} 7$ combination isomerizes the $Z$ isomer into the $E$ isomer. No reaction or an erosion in yield was observed when $\mathbf{N i - 1}$ or $\mathrm{Ni}(\mathrm{COD})_{2} / \mathbf{L} 7$ were exposed to 1a without Mn. See ref 15.

(29) Nett, A. J.; Zhao, W.; Zimmerman, P. M.; Montgomery, J. J. Am. Chem. Soc. 2015, 137, 7636.

(30) In the absence of L7, Mn or TBAB, low yields of monocarboxylic acids were observed in the crude mixtures.

(31) Nickel (I) species have been reported to rapidly react with $\mathrm{CO}_{2}$ : Menges, F. S.; Craig, S. M.; Tötsch, N.; Bloomfield, A.; Ghosh, S.; Krüger, H. J.; Johnson, M. A. Angew. Chemie Int. Ed. 2016, 55, 1282. See ref 15 for control experiments with radical inhibitors.

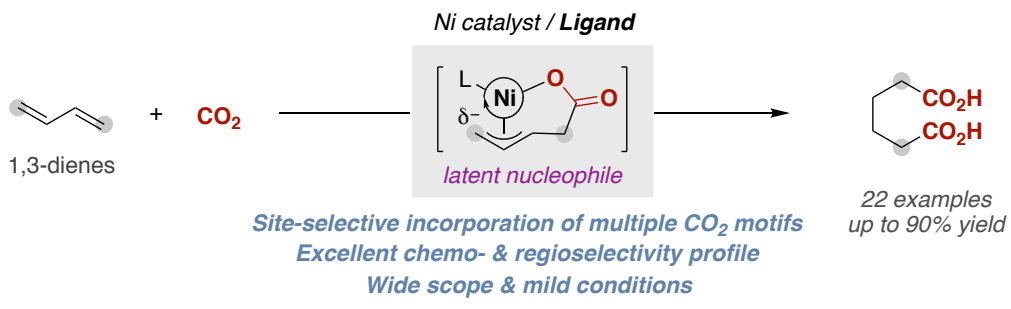

